Research Paper

\title{
Recombinant Human Adiponectin as a Potential Protein for Treating Diabetic Tendinopathy Promotes Tenocyte Progenitor Cells Proliferation and Tenogenic Differentiation In Vitro
}

\author{
Hussin A. Rothan1, Abdulrazzaq Mahmod Suhaeb², Tunku Kamaru12,3凶 \\ 1. Department of Molecular Medicine, Faculty of Medicine, University of Malaya, 50603 Kuala Lumpur, Malaysia. \\ 2. Tissue Engineering Group, Department of Orthopaedic Surgery, NOCERAL, Faculty of Medicine, University of Malaya, Kuala Lumpur, \\ Malaysia. \\ 3. Clinical Investigative Centre (CIC), University Malaya Medical Centre, Kuala Lumpur, Malaysia
}

$\triangle$ Corresponding author: Prof. Tunku Kamarul, Tissue engineering group (TEG), Department of Orthopaedic Surgery, NOCERAL, Faculty of Medicine, University of Malaya, 50603 Kuala Lumpur; tkzrea@um.edu.my

(c) Ivyspring International Publisher. This is an open-access article distributed under the terms of the Creative Commons License (http://creativecommons.org/ licenses/by-nc-nd/3.0/). Reproduction is permitted for personal, noncommercial use, provided that the article is in whole, unmodified, and properly cited.

Received: 2013.05.27; Accepted: 2013.II.13; Published: 2013.11.27

\begin{abstract}
Adiponectin is an adipocyte-secreting hormone that increases cell sensitivity to insulin. It has been previously demonstrated that this hormone protects against Type II Diabetes and, is found to concurrently promote cell proliferation and differentiation. It is postulated that diabetic patients who suffer from tendinopathy may benefit from using adiponectin, which not only improves the metabolism of diabetic ridden tenocytes but also promotes progenitor cell proliferation and differentiation in tendons. These changes may result in tendon regeneration, which, in diabetic tendinopathy, is difficult to treat. Considering that such findings have yet to be demonstrated, a study was thus conducted using diabetic ridden human tenocyte progenitor cells (TPC) exposed to recombinant adiponectin in vitro. TPC were isolated from tendons of diabetic patients and exposed to $10 \mu \mathrm{g} / \mathrm{ml}$ adiponectin. Cell proliferation rate was investigated at various time points whilst $\mathrm{QPCR}$ were used to determine the tenogenic differentiation potential. The results showed that adiponectin significantly reduced blood glucose in animal models. The proliferation rate of adiponectin-treated TPCs was significantly higher at 6, 8 and 10 days as compared to untreated cells $(p<0.05)$. The levels of tenogenic genes expression (collagen I, III, tenomodulin and scleraxis) were also significantly upregulated; whilst the osteogenic (Runx2), chondrogenic (Sox9) and adipogenic (PPARY $Y$ ) gene expressions remained unaltered. The results of this study suggest that adiponectin is a potential promoter that not only improves diabetic conditions, but also increases tendon progenitor cell proliferation and differentiation. These features supports the notion that adiponectin may be potentially beneficial in treating diabetic tendinopathy.
\end{abstract}

Key words: Adiponectin, Tenocyte progenitor cells, Tissue engineering, tenogenic differentiation, diabetic tendinopathy

\section{Introduction}

Due to the chronic metabolic insult to the somatic cells of patients with Type II diabetes, it is not unexpected for the cells and thus the structural properties of connective tissues these cells maintain, to undergo accelerated degenerative changes [1]. It has been shown that particularly in diabetes, changes in tendon properties led to the increase in the prevalence of tendon rupture. This condition is well described in 
many literatures, and is commonly known as diabetic tendinopathy [2]. This pathology is recognized clinically by the increase in tendon stiffness, thickness, and excess calcification of the affected site [3-6]. In addition, several studies have demonstrated that sustained hyperglycaemia affects the metabolisms of all cells including tendon resident cells, also known as tenocytes, which ultimately leads to poor tendon mechanical properties [7, 8] and healing [9].

The use of adiponectin, which is an adipocyte secreting hormone and cytokine, has been shown to not only control type II diabetes and metabolic syndrome by increasing insulin sensitivity of cells, but also improve cell proliferation and differentiation [10-13]. These effects however, have not been demonstrated in diabetic ridden tendon progenitor cells, which may prove to be beneficial in diabetic patients since adiponectin not only addresses the metabolic issues of diabetic ridden cells but will also improve tissue regeneration. A study was thus conducted to investigate the effects of recombinant adiponectin on the proliferation and differentiation of tenocyte progenitor cells form diabetic patients, which if successful, may prove to be a potential therapeutic agent for treating diabetic tendinopathy.

\section{Materials and methods}

\section{Gene construction and cloning}

Adiponectin gene reference sequence was obtained from GenBank (NC_000003.10). The coding region of adiponectin gene (partial exon 2 and exon 3 ) was amplified individually by PCR using human genomic DNA as a template. The two fragments were then joined by overlap-extension PCR procedures. The resulting DNA fragment was then cloned in pGEM ${ }^{\circledR}-\mathrm{T}$ cloning vector. After sequence verification, the recombinant plasmid was double digested with BamHI and HindIII and digested fragments were purified using the QIAquick Gel Extraction kit (QIAGEN, Germany) as described in the manufacturer's protocol. The full-length adiponectin DNA fragment was cloned into pTrcHis vector (Invitrogen, USA) and transformed into Escherichia coli BL21.

\section{Protein expression}

Recombinant E. coli were grown on solid LB/ampicillin $(100 \mu \mathrm{g} / \mathrm{ml})$ plates at $37^{\circ} \mathrm{C}$ overnight. A single colony was selected to inoculate $10 \mathrm{ml}$ to start cell culture. The starter culture was centrifuged at $3000 \mathrm{rpm}$ for $10 \mathrm{~min}$ and the cell pellet was resuspended in $10 \mathrm{ml} \mathrm{LB}$. One litre LB/ampicillin (100 $\mu \mathrm{g} / \mathrm{ml}$ ) were inoculated with starter culture and incubated at $37^{\circ} \mathrm{C}$ until $\mathrm{OD}^{600}$ was approximately 0.5 . Expression of recombinant protein was induced by adding isopropylthiogalactoside (IPTG) to a final concentration of $0.5 \mathrm{mM}$ and expression was continued for $6 \mathrm{~h}$ at $37^{\circ} \mathrm{C}$. A sample of one $\mathrm{ml}$ was taken before and after induction for analysis using SDS-PAGE.

\section{Protein purification}

Protein samples were purified by His GraviTrap ${ }^{\mathrm{TM}}$ Flow (Amersham Biosciences, USA) column containing pre-charged $\mathrm{Ni}$ Sepharose ${ }^{\mathrm{TM}} 6$ Fast. In brief, cell pellet was collected by centrifugation and resuspended in column buffer $(20 \mathrm{mM}$ sodium phosphate buffer and $500 \mathrm{mM} \mathrm{NaCl}, \mathrm{pH} 7.4$ ). Cell suspension was subjected to 3 cycles of freeze and thaw then supernatant was collected after centrifugation at $10,000 \mathrm{rpm}, 4^{\circ} \mathrm{C}$ for 30min. The column was normalized with $10 \mathrm{ml}$ of phosphate buffer $(20 \mathrm{mM}$ sodium phosphate buffer and $500 \mathrm{mM} \mathrm{NaCl}, \mathrm{pH} 7.4$ ). The sample $(6 \mathrm{ml})$ was loaded into the column and the column was washed with $10 \mathrm{ml}$ of binding buffer (phosphate buffer containing $20 \mathrm{mM}$ imidazole, $\mathrm{pH}$ 7.4). The recombinant protein was eluted with $4 \mathrm{ml}$ of elution buffer (phosphate buffer containing $200 \mathrm{mM}$ imidazole, $\mathrm{pH}$ 7.4).

\section{Western immunoblotting}

Protein samples were loaded into $12 \%$ gels SDS-PAGE, and then transferred to a nitrocellulose membrane $(1 \mathrm{~h}, 100 \mathrm{~V})$. Following the transfer, the membrane was blocked in Tris Buffered Saline with Tween-20 containing $50 \mathrm{~g} / \mathrm{L}$ skimmed milk for $2 \mathrm{~h}$, and then incubated with first monoclonal antibody for $2 \mathrm{~h}$ at room temperature. The membrane was washed three times with Tris Buffered Saline (15 min each time) and then incubated with secondary antibody conjugated with alkaline phosphatase for $2 \mathrm{~h}$. The membrane was then washed again with Tris Buffered Saline as described previously, and finally developed using Western Blue ${ }^{\circledR s t a b i l i z e d ~ s u b s t r a t e ~(P r o m e g a, ~}$ USA). Relative quantification of protein markers compared to untreated control were analyzed using Image J software.

\section{Recombinant Adiponectin Bioactivity}

Experiments to assess the bioactivity of recombinant adiponectin were conducted on ICR female mice. To study the effect of adiponectin dosage on blood glucose and lipids, three groups of mice $(n=6$ each) were fasted for 4 hours, before being gavaged with high fat-sucrose diet $(v=0.1 \% \quad B W)$. Intra-peritoneal injection of adiponectin was done immediately after feeding at $1.25 \mathrm{mg} / \mathrm{kg}$ body-weight for low-dose treatment and $2.5 \mathrm{mg} / \mathrm{kg}$ body-weight for high-dose treatment. One group of mice was injected with $0.5 \mathrm{ml}$ saline as control. Blood glucose was 
measured using a glucometer hourly for four hours. For oral glucose tolerance test experiments, two groups of animals were fasted overnight and then received oral glucose challenge $(2 \mathrm{~g} / \mathrm{kg}$ body-weight, via gavaging). Injection of $2.5 \mathrm{mg} / \mathrm{kg}$ body-weight of adiponectin was done immediately after gavaging, and glucose level was measured from blood collected through tail bleeds at 1, 2 and 3 hours.

\section{Isolation of tenocyte progenitor cells (TPCs)}

Study was conducted in accordance to the ethics approved protocol by University of Malaya Medical Centre ethics approval board (Reference No. 602.22). Tenocytes were isolated from discarded human tendon specimens from amputated lower limbs of established Type II diabetic mellitus patients $(n=3)$ i.e. for more than 5 years on therapy, following methods described previously $[14,15]$. In brief, the tissue sample was subjected to enzymatic digestion using $3 \mathrm{mg}$ collagenase type I (Sigma, USA) in $1 \mathrm{ml}$ phosphate buffered saline (PBS) at $37^{\circ} \mathrm{C}$ for $1 \mathrm{hr}$. The cell pellets was resuspended in growth medium consisting of Dulbecco's modified Eagle's medium (DMEM; Gibco -Invitrogen, USA) supplemented with $20 \%$ fetal bovine serum (FBS; Gibco -Invitrogen, USA), $100 \mu \mathrm{M}$ 2-mercaptoethanol (Sigma-Aldrich, USA), $100 \mathrm{U} / \mathrm{ml}$ penicillin and $100 \mathrm{\mu g} / \mathrm{ml}$ streptomycin (Gibco -Invitrogen, USA) and incubated at standard conditions (humidified atmosphere, $5 \% \mathrm{CO} 2,37^{\circ} \mathrm{C}$ ) for enough expansion. The flasks with confluent cells were trypsinized using $0.25 \%$ trypsin (Invitrogen, USA) and a single-cell suspension of 1 cell $/ \mu$ l was prepared and cultured in $\mathrm{T} 75$ flasks at $37^{\circ} \mathrm{C}$ with $5 \%$ CO2. The TPCs were able to form colonies after 14 days while the elongated tenocytes failed to spread as individual cells. The individual tenocytes around the colonies were detached using $0.1 \%$ trypsin prepared in PBS and applied for $15 \mathrm{~min}$. The detached cells were collected by micropipette and subcultured in new T25 flasks. The remaining colonies were detached using $0.25 \%$ trypsin for $10 \mathrm{~min}$ and transferred to another T25 flasks for further expansion, with the addition of regular growth medium (DMEM plus 10\% FBS).

\section{Cell proliferation and differentiation}

Tenocyte progenitor cells were extended to passage 3 and plated at $10^{4}$ / well in 6 well plates. FBS free DMEM medium was supplemented with $10 \mu \mathrm{g} / \mathrm{ml}$ adiponectin for the treatment group (5 plates) whilst the medium of control group (5 plates) was supplemented with bovine serum albumin (BSA). Proliferation rates were determined at 2, 4, 6, 8 and 10 days. At each time point, the cell count of treatment and control plates ( 2 plates, 6 replicate each) were performed using hemocytometer. Population doubling time was used to determine the proliferation rate as a total culture time divided by the number of generations. The number of generations was calculated as $\log 2 \mathrm{Nc} / \mathrm{N} 0$ where Nc is the population at confluence while N0 is the population of initially seeded cells.

\section{Gene expression analysis}

Real time PCR was used to study the expression level of tenogenic gene markers collagen I, collagen III, tenomodulin and scleraxin as well as other gene markers like osteogenic gene marker Runx2, chondrogenic gene marker Sox9 and adipogenic gene marker PPARY to determine if cells had drifted into an unwanted lineages i.e. osteogenic, chondrogenic and adipogenic lineages. The TPCs were plated at 106/ T75 flask and maintained in FBS free DMEM medium supplemented with $10 \mu \mathrm{g} / \mathrm{ml}$ adiponectin (Treatment group) or BSA (Control group). Cells were harvested after $48 \mathrm{hrs}$ and total RNA was extracted using RNA extraction kit (Promega, USA). Reverse-transcription was performed using cDNA synthesis kit (Invitrogen, USA) to prepare first strand cDNA that was used as template for RT-PCR analysis using SYBR Green PCR kit (BioRad, USA). The PCR program consisted of an initial step of 10 seconds at $95^{\circ} \mathrm{C}$, followed by 40 cycles of denaturing at $95^{\circ} \mathrm{C}$, annealing at $50^{\circ} \mathrm{C}$ for 5 seconds and extension at $60^{\circ} \mathrm{C}$ for 31 seconds. The relative level of genes expression was quantified using the $\beta$-actin gene as an endogenous control.

\section{Results}

\section{Adiponectin cloning and production in E. coli}

The full length DNA fragment of adiponectin was constructed by overlapping exon 2 (204 bp) with exon $3(531 \mathrm{bp})$ to get the entire adiponectin coding sequence of $734 \mathrm{bp}$ that was cloned into $E$. coli expression vector pTrcHis (Fig. 1A). The recombinant $E$. coli cells that harbour the expression vector pTrcHis-Adiponectin were able to produce the recombinant adiponectin $(30 \mathrm{kDa})$ as a soluble protein after induction with IPTG (Fig. 1B). Western blot analysis using anti-adiponectin antibody confirmed that the purified recombinant adiponectin was produced in a trimer protein by E. coli (Fig. 1C).

\section{Adiponectin bioactivity}

To confirm the biological activity of recombinant adiponectin, ICR mice were fed with high fat-sucrose diet and injected with recombinant adiponectin. Adiponectin were able to reduce blood glucose levels significantly $(p<0.01)$ at all time points (Fig. 2A). The ability of recombinant adiponectin in reducing blood glucose levels was also evaluated by 
glucose tolerant test. The results showed that the recombinant adiponectin significantly $(p<0.01)$ reduced blood glucose after 1, 2 and $3 \mathrm{hrs}$ of gavaging overnight fasting animals with $2 \mathrm{~g} / \mathrm{kg}$ glucose (Fig. 2B).

\section{Isolation of tenocyte progenitor cells}

A single-cell suspension of 1 cell $/ \mu 1$ was cultured in normal growth medium (Fig 3A). The rounded shape cells were able to form small colonies after 7 days whilst the elongated cells remained quiescent (Fig. 3B and 3C). Colonies diameter increase gradually from 7 to 14 days and many colonies were different in size and shape, which occupied most of culture flask. However, the elongated tenocyes spread individually among the colonies that were easily detached by low concentration trypsin and cultured in new flasks. Colonies contain compact central and peripheral cells without recognized border (Fig. 3D). However, isolated peripheral cells exhibited higher growth rate than the central cells (data not shown). After three passages, TPCs exhibited cobblestone shape (Fig. 3E) whilst mature tenocytes maintained its elongated shape (Fig. 3F).
(A)

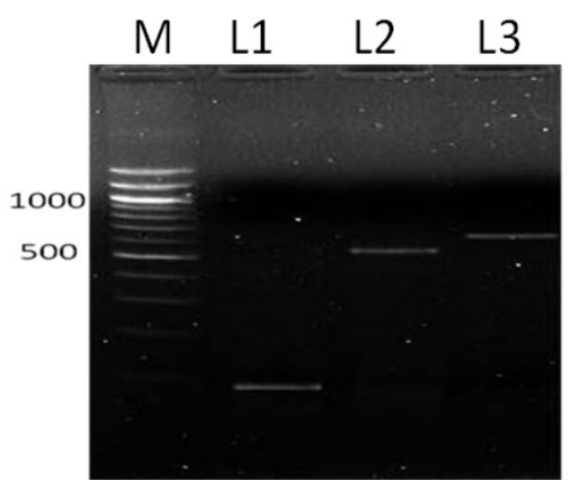

(B)

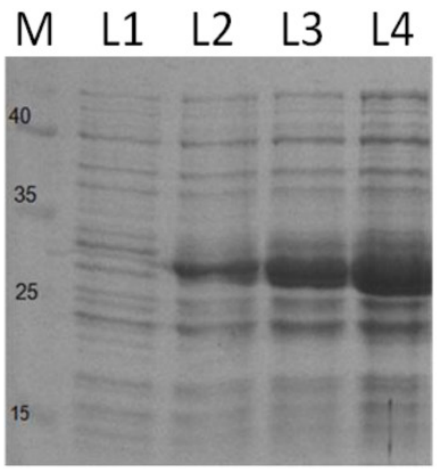

(C)

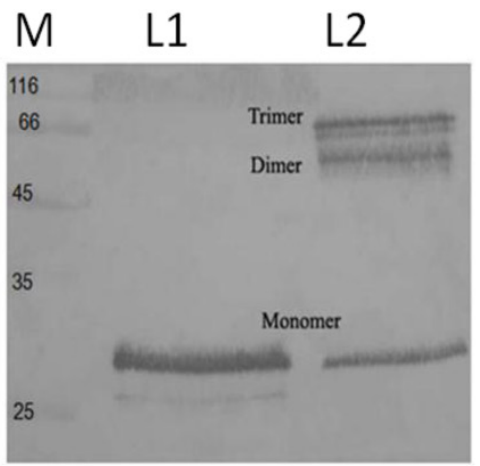

Figure I. Production of recombinant adiponectin as a soluble protein by $E$. coli. (A) The construction of adiponectin DNA fragment by overlapping exon 2 with exon 3 using overlapping extension PCR (LI, exon 2; L2, exon 3; L3, Full length DNA). (B) The SDS-PAGE analysis of adiponectin production in E. coli. Before IPTG induction, the recombinant protein was not detectable (LI) whereas the band density of recombinant protein was increase gradually after 2, 4 and 6 hrs of IPTG induction ( $L$ 2, L3 and L4). (C) The Western blot analysis of adiponectin molecules under reducing and non-reducing condition. The molecular weight of recombinant adiponectin was approximatly $30 \mathrm{kDa}(\mathrm{LI})$ and higher molecular weights of adiponectin were detected as a dimer and trimer (L2 and L3).

(A)

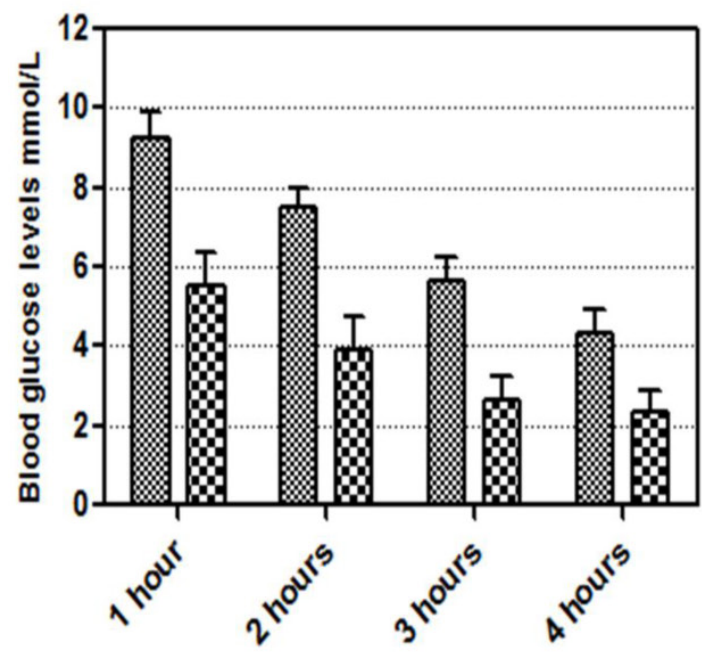

(B)

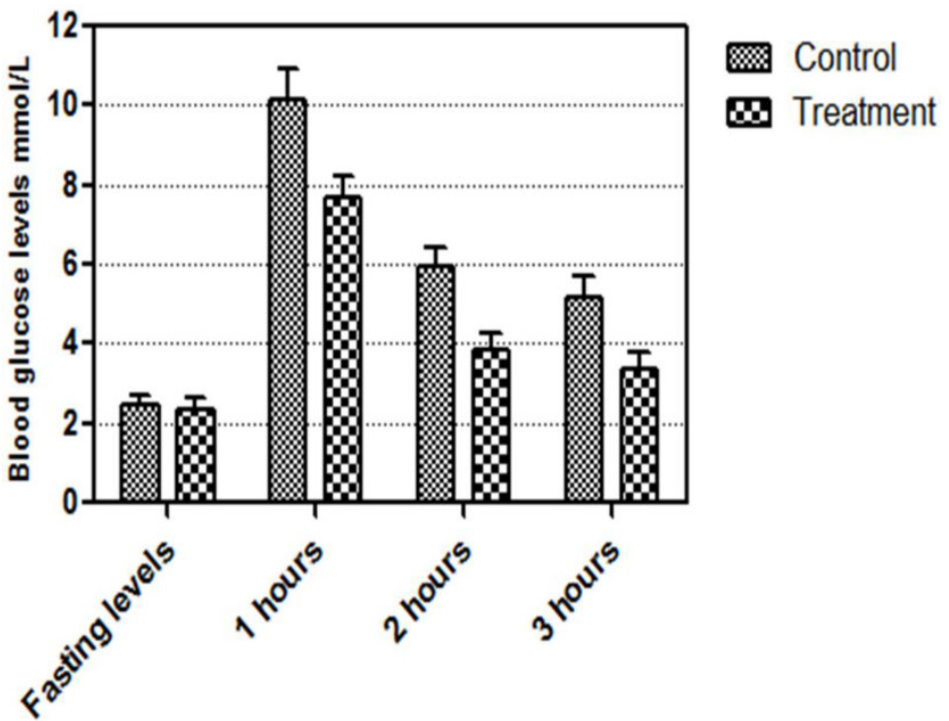

Figure 2. Blood glucose lowering in ICR mice by recombinant adiponectin. (A) The mice were fed with high fat-sucrose diet ( $\mathrm{V}=0 . \mathrm{I} \% \mathrm{BW}$ ) and injected with $2.5 \mathrm{mg} / \mathrm{kg}$ of recombinant adiponectin. Blood glucose was measured after I, 2, 3 and 4 hrs. Adiponectin were significantly ( $\mathrm{P}<0.0 \mathrm{I}$ ) lowered blood glucose at the four time points $(p<0.0 \mathrm{I})$. (B) The mice were gavaged with glucose $(2 \mathrm{~g} / \mathrm{kg})$ after overnight fasting and treated immediately with adiponectin $(2.5 \mathrm{mg} / \mathrm{kg})$. Glucose level was measured from blood collected through tail bleeds at I, 2 and 3 hours. Blood glucose was lowered significantly $(p<0.0 \mathrm{l})$ at all time points. 
(A)

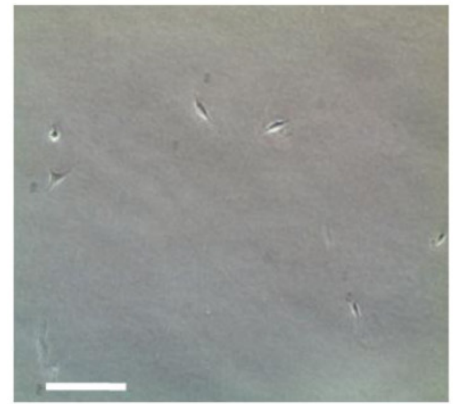

(D)

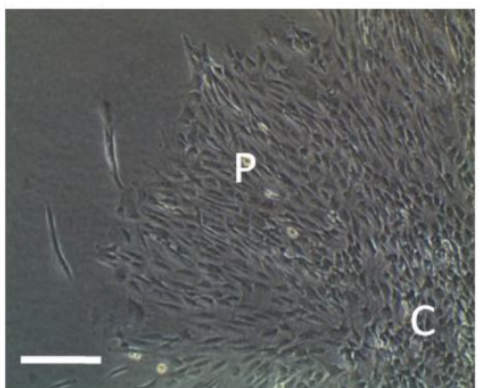

(B)

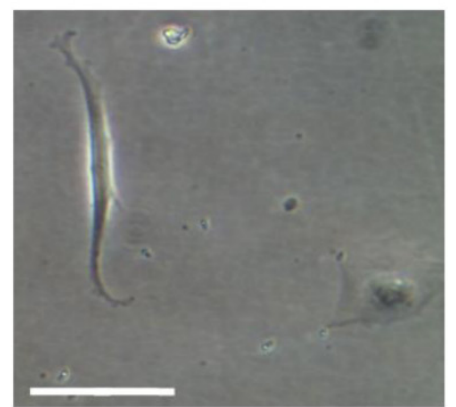

(E)

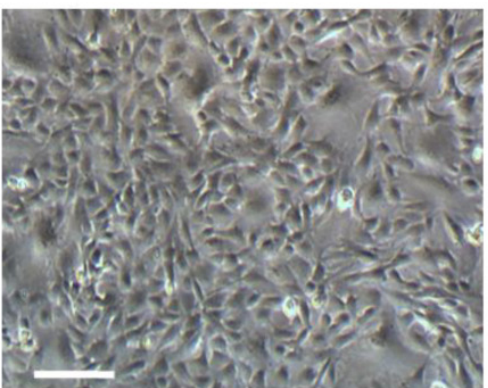

(C)

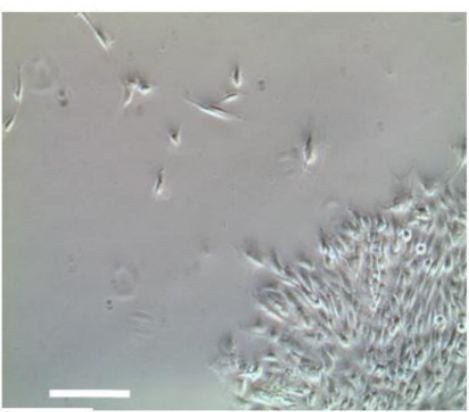

(F)

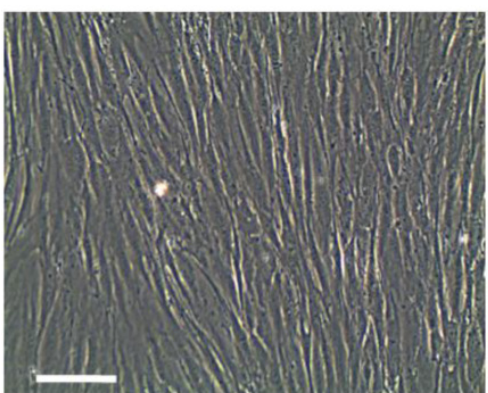

Figure 3. Isolation of tenocyte progenitor cells. A single-cell suspension of I cell/ $\mu$ l was prepared and cultured in $\mathrm{T} 75$ flasks at $37^{\circ} \mathrm{C}$ with $5 \% \mathrm{CO} 2$ (A). The rounded cells were able to form colonies after I 4 days while the elongated tenocytes were failed and spread as individual cells (B and $C$ ). The colonies comprised of central compact cell and peripheral cells (D). To separate the individual tenocytes, $0.1 \%$ trypsin prepared in PBS was applied for I 5 min. The detached cells were collected by micropipette and subcultured in new T25 flasks. The remained colonies were detached $0.25 \%$ trypsin for 10 min and transferred to other T75 flasks for further expansion with addition of regular growth medium. After three passages, TPCs exhibited cobblestone shape (E) whilst mature tenocytes maintained its elongated shape $(F)$. (Bars: $50 \mu \mathrm{m})$. $P=$ Peripheral cells, $C=C e n t r a l$ cells

\section{The effect of adiponectin on TPCs prolifera- tion}

Adiponectin dosage and the time points in this study were chosen based on pilot experiments that were carried out first as a preliminary study (data not shown). Tenocyte progenitor cells were plated on $10^{4} /$ well in 6 well plates and supplemented with $10 \mu \mathrm{g} / \mathrm{ml}$ adiponectin for the treatment group whilst the control group was supplemented with bovine serum albumin (BSA) as descried previously [13]. Cells count after treatment with adiponectin remained similar at day 2 and 4 as compared with control. However, there was gradual significant increase in cell proliferation at 6,8 and 10 days of treatment group as compared with control (Fig. 4A). After 10 days treatment with adiponectin, the population doubling time decreased and cells growth rate increased significantly $(p<0.05)$ as compared with control group (Fig. 4B).

\section{Gene expression analysis}

Tenocyte progenitor cells were harvested after incubation for $48 \mathrm{hrs}$ with adiponectin. Total RNA was extracted and complementary DNA was generated by reverse transcriptase. Different sets of primers were designed to amplify specific fragments of each gene of interest and $\beta$-actin as endogenous gene (Fig. 5). While the expression levels of PPARy, SOX9 and Runx2 were unaltered (Fig 5A), there was remarkable increase in the expression levels of tenogenic markers after treatment with recombinant adiponectin (Fig 5B). Relative quantification data showed that collagen I, Collagen III, tenomodulin and scleraxis showed significant upregulation compared to control (2.0 fold $\pm 0.3,1.73$ fold $\pm 0.25,1.63$ fold \pm 0.21 and 1.74 fold $\pm 0.24)$, while insignificant changes were observed in the expression levels of PPARy, SOX9 and Runx2 (Fig 5C). These results was confirmed by Western blot analysis that showed significant up-regulation in the protein expression of tenogenic markers Collagen I, Collagen III, tenomodulin and scleraxis $(2.26$ fold \pm $0.24,2.06$ fold $\pm 0.22,1.53$ fold \pm 0.17 and 1.60 fold \pm 0.12 respectively) with no changes in the expression levels of PPARy, Runx2 or SOX9 (Fig. 6).

\section{Discussion}

Previous studies have demonstrated that adiponectin provides protection against metabolic syndrome by increasing insulin sensitivity of cells thus reducing the sustained condition of hyperglycaemia 
observed in most diabetic patients. The development of this protein over recent years have been remarkable, making adiponectin a likely candidate to be developed as a potential drug for treating diabetes in the near future [10, 16, 17]. It has been shown that the incidence of tendinopathy increases in diabetic patients, mainly attributed to insulin insensitivity of tenocytes [18]. Known as diabetic tendinopathy, affected tendons appear to have an increase in stiffness, thickness, excess calcification and poor neovascularisation $[3,4,6]$. These changes have been attributed to the structural disorganisation of collagen fibres because of the low expression level in collagen remodelling enzymes especially MMP-3 and the down regulation in collagen I and III [19]. Moreover, collagen solubility is altered by high level of free glucose mol-

(A)

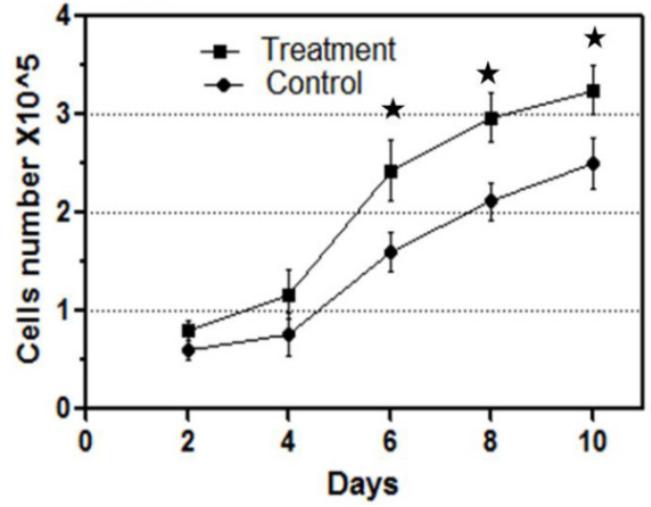

ecules that attaches to collagen and thus increases the resistance of affected tendon to undergo remodelling by enzymatic degradation [20]. It is interesting to note that the present study offers a unique perspective of which the use of adiponectin not only addresses the issue of insulin insensitivity of cells in diabetic patients, such as TPC, but also open new prospects of being used as a potential inducer that increases cell proliferation and differentiation rates. This in turn improves tissue repair outcomes when used in specific conditions such as diabetic tendinopathy. As far as the authors of this paper are aware this is the first study that has reported such findings, indicating that this cytokine may have role in future clinical applications.

(B)

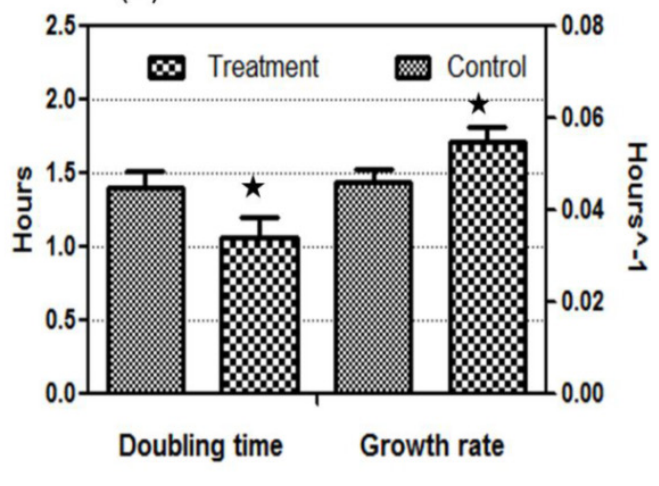

Figure 4. The effect of adiponectin treatment on TPCs proliferation rate. The TPCs were extended to passage 3 and plated at $10^{4} /$ well in 6 well plates. FBS free DMEM medium was supplemented with $10 \mu \mathrm{g} / \mathrm{ml}$ adiponectin or BSA as control. (A) Cells number increased significantly 6,8 and 10 days compared to control. (B) After adiponectin treatment, population doubling time decreased and cells growth rate increased indicating that adiponectin treatment enhanced TPCs proliferation rate. * significant at 0.05 level.

(A)

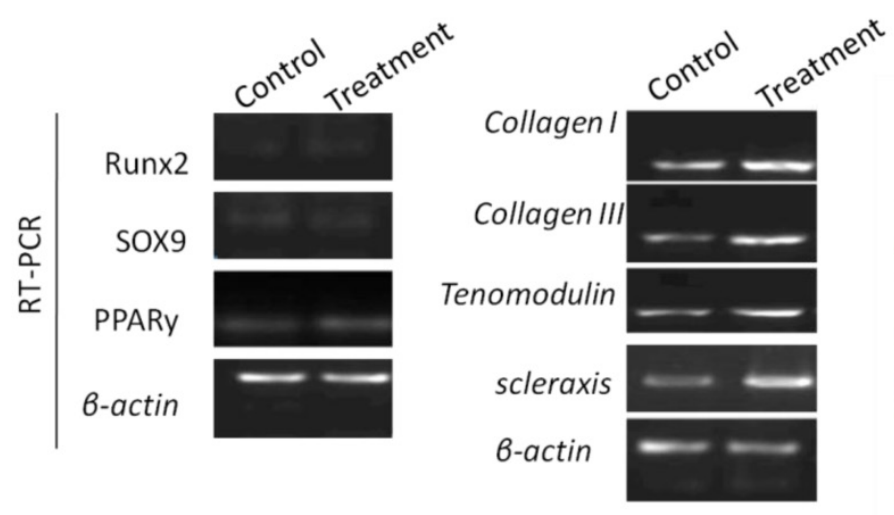

(C)

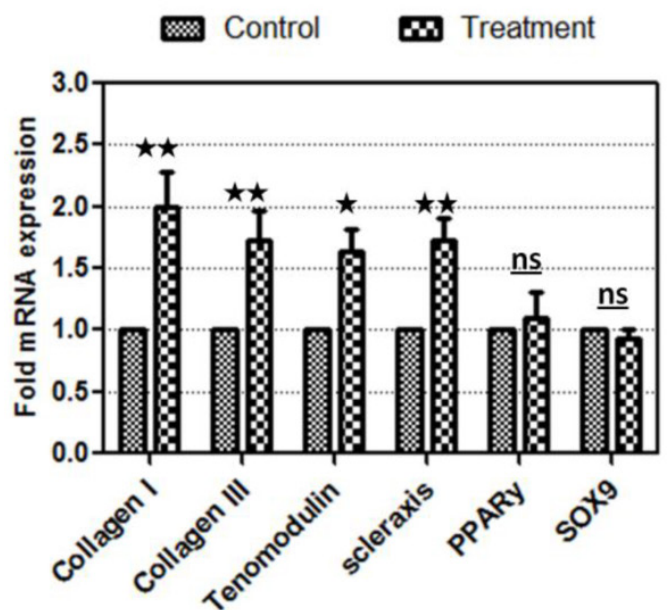

Figure 5: Analysis of gene expression in adiponectin-treated cells. (A) The TPCs showed low expression levels of osteogenic (Runx2), chondrogenic (Sox9) and adipogenic (PPARY) gene markers which were not affected by treatment. (B) The expression of collagen I, Collagen III, tenomodulin and scleraxis were significantly higher than control. (C) Relative quantification of gene markers compared to untreated control, which was defined as I.0 fold, and then normalized to $\beta$-actin reference gene. Tenogenic gene markers Collage I, Collage III, tenomodulin and scleraxis showed significant upregulation compared to control ( 2.0 fold \pm 0.3 , I.73 fold \pm 0.25 , I.63 fold \pm 0.21 and 1.74 fold \pm 0.24$)$. Results are expressed as mean \pm SD from triplicate experiments. (** Significant at $0.01, *$ significant at $\mathrm{P}<0.05$, ns: not significant). 
(A)

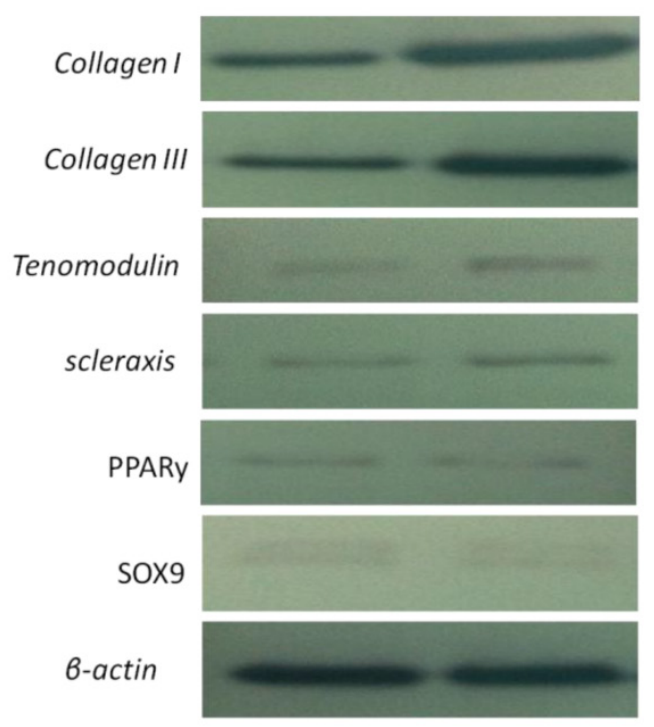

(B)

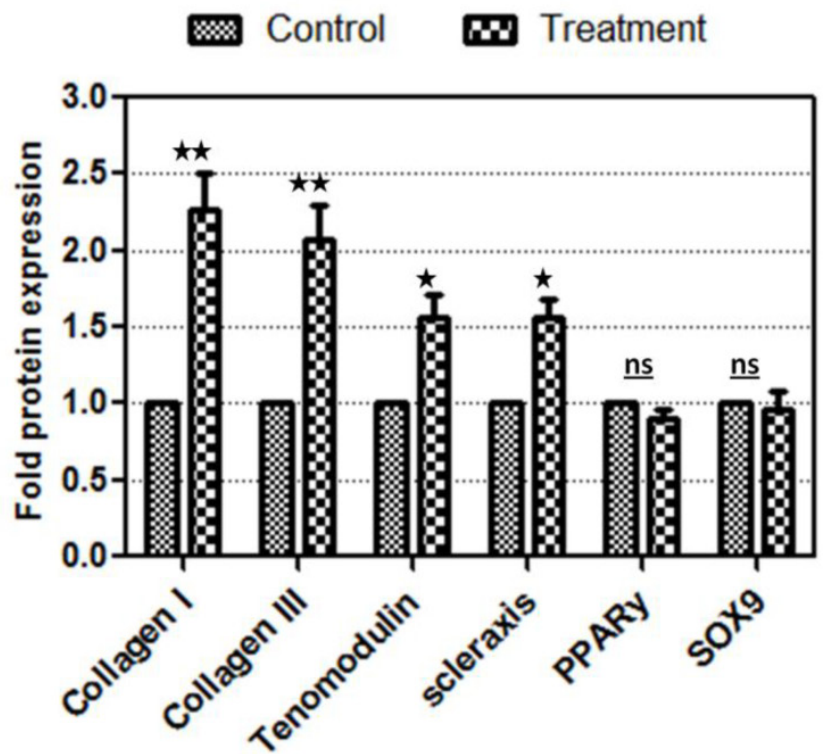

Figure 6: Evaluation of tenogenic differentiation in adiponectin-treated cells by Western blot. (A) Proteins were separated by SDS-PAGE and transferred on the cellulose membranes to develop bands after incubation with specific antibodies. (B) Relative quantification of protein markers compared to untreated control using image analysis (Image J), which was defined as I.0 fold, and then normalized to $\beta$-actin reference protein. Collagen I, collagen III, tenomodulin and scleraxis significantly upregulated ( 2.26 fold $\pm 0.24,2.06$ fold \pm 0.22 , 1.53 fold \pm 0.17 and 1.60 fold \pm 0.12 respectively). No significant changes were observed in the expression of PPARy and SOX 9 while Runx 2 was undetectable. Results are expressed as mean \pm SD from triplicate experiments. (** significant at 0.01 , * significant at $\mathrm{P}<0.05$, ns: not significant).

The findings of this study demonstrated that not only was the tenogenic gene marker tenomodulin and scleraxis as well as collagen I and III were upregulated, the gene markers of other lineages (chondrocyte, adipocyte and osteocyte) were not affected suggesting that it is most likely the case that adiponectin will not cause ectopic tissue formation when used in vivo. The implications of this finding are wide ranging, among which it appears to suggest that better clinical outcomes can be expected when applied in patients with diabetic tendinopathy. Previous studies have demonstrated that by using conventional repair methods, chondrocyte-like cells are observed to be of the dominant cell type at the insertion of ruptured Achilles tendon in diabetic patients [21]. It is thus suggested that this may the reason as to why tendon rupture occurs, namely because of the area of repair may have inappropriate mechanical properties that is unable to withstand the tensional mechanical loading imposed during normal activities [22, 23]. Additionally, it has also been demonstrated that in the absence of some tenogenic markers in damaged sites that were treated using conventional methods, tendon tend to develop tissues which have disorganized collagen fibre arrangements. This further contributes to the likelihood of a rupture developing in these sites [24]. The upregulation of this gene in TPC treated with adiponectin indicates that this may no longer be an issue if adiponectin is applied concurrently during tendon repair. However, despite all these promising indicators, the efficacy of adiponectin will still need to be proven using more robust experiments possibly involving pre-clinical models or even pilot human studies. At the time this paper is written, these initiatives are presently being conducted and hopefully will be reported in the near future.

The mechanism by which adiponectin results in cell proliferation and more importantly induces specific lineage differentiation has yet to be demonstrated although, the mechanism by which this hormone results in increased insulin sensitivity in cells have been largely described [25-28, 24]. In short, the globular domain adiponectin mainly acts on adipoR1 whereas the full-length adiponectin is able to influence both adipoR1 and adipoR2 receptors [29]. Through these receptors, adiponectin stimulate glucose uptake and fatty acid oxidation through the activation of AMPK (AMP-activated protein kinase) and p38 mitogen-activated protein kinase (MAPK) [29]. In the present study, the full-length recombinant adiponectin produced in E. coli as a trimeric isoform had the ability to reduce blood glucose levels in animals fed with high fat-sucrose diet or administrated with high glucose levels, which was similar to that reported by others [27]. It is one limitation that in the present study, we were not able to demonstrate that the in vitro TPC had better glucose uptake when adiponectin were used, which will indicate that these cells may 
have better metabolism rate hence resulting in the tenogenic genes being upregulated. Keeping in mind that another argument to this would be the fact that tendon-derived cells, such as TPC, may have low metabolism rate to begin with and therefore may not be affected when adiponectin is introduced in tendons. Again, this can only be demonstrated using an appropriate in vivo model since the present study was not designed to address these issues.

In conclusion, in addition to lowering glucose levels, adiponectin has demonstrated the ability to improve tenocyte progenitor cells proliferation and differentiation, which makes it a potential therapeutic agent in treating diabetic tendinopathy.

\section{Acknowledgment}

This study was supported by HIR-MOHE research grant initiative.

\section{Competing Interests}

The authors have declared that no competing interest exists.

\section{References}

1. Del Buono A, Battery L, Denaro V, Maccauro G, Maffulli N. Tendinopathy and inflammation: some truths. Int J Immunopathol Pharmacol. 2011;24(1 Suppl 2):45-50.

2. El Zahran T, Collins K, Terk MR. Bilateral spontaneous rupture of the flexor digitorum superficialis and the flexor digitorum profundus in a diabetic patient. Skeletal Radiol. 2013 Feb;42(2):297-301.

3. Battery L, Maffulli N. Inflammation in overuse tendon injuries. Sports Med Arthrosc. 2011 Sep;19(3):213-217.

4. Burner T, Gohr C, Mitton-Fitzgerald E, Rosenthal AK. Hyperglycemia reduces proteoglycan levels in tendons. Connect Tissue Res. 2012;53(6):535-41

5. Cheing GL, Chau RM, Kwan RL, Choi CH, Zheng YP. Do the biomechanical properties of the ankle-foot complex influence postural control for people with Type 2 diabetes? Clin Biomech (Bristol, Avon). 2013 Jan;28(1):88-92.

6. Abate M, Schiavone C, Salini S. Neoangiogenesis is reduced in chronic tendinopathies of type 2 diabetic patients. Int J Immunopathol Pharmacol. 2012;25(3):757-61.

7. de Oliveira RR, de Lira KD, Silveira PV, Coutinho MP, Medeiros MN, Teixeira MF, de Moraes SR. Mechanical properties of achilles tendon in rats induced to experimental diabetes. Ann Biomed Eng. 2011 May;39(5):1528-34.

8. de Oliveira RR, Bezerra MA, de Lira KD, Novaes KA, Teixeira MF, Chaves Cde C, Moraes SR. Aerobic physical training restores biomechanical properties of Achilles tendon in rats chemically induced to diabetes mellitus. J Diabetes Complications. 2012;26(3):163-8.

9. Bedi A, Fox AJ, Harris PE, Deng XH, Ying L, Warren RF, Rodeo SA. Diabetes mellitus impairs tendon-bone healing after rotator cuff repair. J Shoulder Elbow Surg. 2010 Oct;19(7):978-88.

10. Kadowaki T, Yamauchi T, Kubota N, Hara K, Ueki K, Tobe K. Adiponectin and adiponectin receptors in insulin resistance, diabetes, and the metabolic syndrome. J Clin Invest. 2006 Jul;116(7):1784-92.

11. Garaulet M, Viguerie N, Porubsky S, Klimcakova E, Clement K, Langin D, Stich V. Adiponectin gene expression and plasma values in obese women during very-low-calorie diet. Relationship with cardiovascular risk factors and insulin resistance. J Clin Endocrinol Metab. 2004 Feb;89(2):756-60.

12. Li CJ, Sun HW, Zhu FL, Chen L, Rong YY, Zhang Y, Zhang M. Local adiponectin treatment reduces atherosclerotic plaque size in rabbits. J Endocrinol. 2007 Apr;193(1):137-45.

13. Yang H, Zhang R, Mu H, Li M, Yao Q, Chen C. Adiponectin promotes endothelial cell differentiation from human peripheral CD14+ monocytes in vitro. J Cell Mol Med. 2006;10(2):459-69.

14. Bi Y, Ehirchiou D, Kilts TM, Inkson CA, Embree MC, Sonoyama W, Li L, Leet AI, Seo BM, Zhang L, Shi S, Young MF. Identification of tendon stem/progenitor cells and the role of the extracellular matrix in their niche. Nat Med. 2007 Oct;13(10):1219-27.

15. Zhang J, Wang JH. Characterization of differential properties of rabbit tendon stem cells and tenocytes. BMC Musculoskelet Disord. 2010 Jan 18;11:10.

16. Hotta K, Funahashi T, Arita Y, Takahashi M, Matsuda M, Okamoto Y, Iwahashi H, Kuriyama H, Ouchi N, Maeda K, Nishida M, Kihara S, Sakai N, Nakajima T, Hasegawa K, Muraguchi M, Ohmoto Y, Nakamura T, Yamashita
S, Hanafusa T, Matsuzawa Y. Plasma concentrations of a novel, adipose-specific protein, adiponectin, in type 2 diabetic patients. Arterioscler Thromb Vasc Biol. 2000 Jun;20(6):1595-9.

17. Yatagai T, Nagasaka S, Taniguchi A, Fukushima M, Nakamura T, Kuroe A, Nakai Y, Ishibashi S. Hypoadiponectinemia is associated with visceral fat accumulation and insulin resistance in Japanese men with type 2 diabetes mellitus. Metabolism. 2003 Oct;52(10):1274-8.

18. Maffulli N, Longo UG, Maffulli GD, Khanna A, Denaro V. Achilles tendon ruptures in diabetic patients. Arch Orthop Trauma Surg. 2011 Jan;131(1):33-8.

19. Ahmed AS, Schizas N, Li J, Ahmed M, Östenson CG, Salo P, Hewitt C, Hart DA, Ackermann PW. Type 2 diabetes impairs tendon repair after injury in a rat model. J Appl Physiol. 2012 Dec 1;113(11):1784-91.

20. Del Buono A, Battery L, Denaro V, Maccauro G, Maffulli N. Tendinopathy and inflammation: some truths. Int J Immunopathol Pharmacol. 2011;24:45-50.

21. Ji J, wang Z, Shi D, Gao X, Jiang Q. Pathologic changes of Achilles tendon in leptin-deficient mice. Rheumatol Int. 2010 Feb;30(4):489-93.

22. Thomopoulos S, Kim HM, Silva MJ, Ntouvali E, Manning CN, Potter R, Seeherman H, Gelberman RH. Effect of bone morphogenetic protein 2 on tendon-to-bone healing in a canine flexor tendon model. J Orthop Res. 2012 Nov;30(11):1702-9.

23. Parent G, Huppé N, Langelier E. Low stress tendon fatigue is a relatively rapid process in the context of overuse injuries. Ann Biomed Eng. 2011 May;39(5):1535-45.

24. Riley GP, Harrall RL, Cawston TE, Hazleman BL, and Mackie EJ. Tenascin-C and human tendon degeneration. Am J Pathol. 1996; 149(3): 933-943.

25. Rothan HA, Teh SH, Haron K, Mohamed Z. A Comparative Study on the Expression, Purification and Functional Characterization of Human Adiponectin in Pichia pastoris and Escherichia coli. Int $\mathrm{J}$ Mol Sci. 2012;13(3):3549-62.

26. Pajvani UB, Du X, Combs TP, Berg AH, Rajala MW, Schulthess T, Engel J, Brownlee M, Scherer PE. Structure-function studies of the adipocyte-secreted hormone Acrp30/adiponectin. Implications fpr metabolic regulation and bioactivity. J Biol Chem. 2003 Mar 14;278(11):9073-85.

27. Kadowaki T, Yamauchi T, Kubota N, Hara K, Ueki K, Tobe K. Adiponectin and adiponectin receptors in insulin resistance, diabetes, and the metabolic syndrome. J Clin Invest. 2006 Jul;116(7):1784-92.

28. Waki H, Yamauchi T, Kamon J, Ito Y, Uchida S, Kita S, Hara K, Hada Y, Vasseur F, Froguel P, Kimura S, Nagai R, Kadowaki T. Impaired multimerization of human adiponectin mutants associated with diabetes. Molecular structure and multimer formation of adiponectin. J Biol Chem. 2003 Oct 10;278(41):40352-63.

29. Tsao TS, Murrey HE, Hug C, Lee DH, Lodish HF. Oligomerization state-dependent activation of NF-kappa B signaling pathway by adipocyte complement-related protein of $30 \mathrm{kDa}$ (Acrp30). J Biol Chem. 2002 Aug $16 ; 277(33): 29359-62$ 